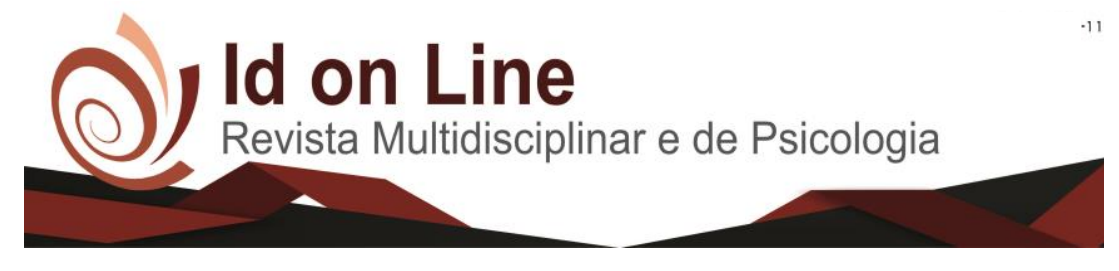

DOI: 10.14295/idonline.v13i46.1999

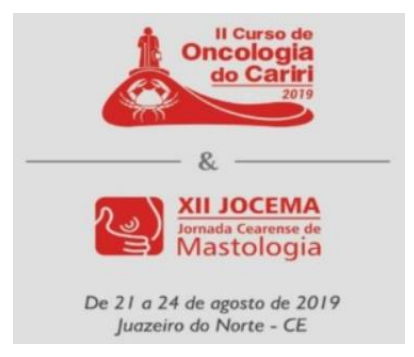

Resumo

\title{
NÓDULO DE PLUMMER: UM RELATO DE CASO
}

\author{
Pedro Augusto Silva da Costa ${ }^{l}$, Gabriel da Fonseca Soares Ferreira ${ }^{l}$, Hélio Fillipe da Silva Ferreira ${ }^{1}$, \\ Pedro Lima Verde Teixeira ${ }^{1}$, Alyne Layane Pereira Lemos ${ }^{2}$
}

Introdução: A doença de Plummer, também conhecida como Adenoma Tireoidiano Tóxico, é um tumor benigno ocasionado pelo crescimento excessivo e a transformação estrutural/funcional de uma área do parênquima tireoidiano, sendo a terceira causa mais comum de hipertireoidismo no Brasil. Trata-se de uma patologia que acomete mais o sexo feminino, em pacientes entre 30 e 60 anos. O quadro clínico consiste em palpitações, insônia, alterações no humor e tremores nas extremidades, presente em nódulos maiores do que $3 \mathrm{~cm}$ de diâmetro. O diagnóstico é feito através da clínica, exames laboratoriais e Cintilografia de Tireoide. O tratamento pode ser feito através de iodo radioativo, drogas antitireoidianas, escleroterapia com etanol ou cirurgia. Objetivo: Relatar o caso de um paciente com diagnóstico de nódulo de Plummer. Relato de Caso: Paciente do sexo masculino, 40 anos, compareceu ao consultório de endocrinologia encaminhado pelo cardiologista devido a episódios de palpitações, com TSH abaixo da normalidade e passado de nódulo na tireoide. Paciente nega perda de peso, alterações de humor e tremores nas extremidades, mas relata insônia. Ao exame físico, apresentou nódulo palpável em lobo direito de tireoide de aproximadamente $3 \mathrm{~cm}$. Exames laboratoriais apontaram TSH 0,21 mU/L e T4 Livre 0,97 ng/dl, caracterizando um hipertireoidismo subclínico. Foi solicitado USG de Tireoide com Doppler o qual apresentou um nódulo misto em LD predominantemente cístico medindo $3,8 \times 3,4 \times 2,3 \mathrm{~cm}$ com TI-RADS 4a. Realizou cintilografia de tireoide evidenciando lobo direito hipercaptante, com supressão do restante do parênquima sugestivo de doença de Plummer. PAAF resultou em Bethesda 2 (bócio colóide) Conclusão: Este caso ilustrou a apresentação clínica de um paciente com hipertireoidismo subclínico devido a doença de Plummer.

Palavras-chave: Tireoide; Nódulo de Plummer; Hipertireoidismo.

1 Acadêmico no curso de medicina Faculdade de Medicina Estácio de Juazeiro do Norte;

${ }^{2}$ Orientadora, Médica Endocrinologista e Docente da FMJ;

Autor correspondente: pedrowaugusto@hotmail.com. 


\section{Referências}

MACIEL, Léa MZ. Adenoma tireoideano tóxico: aspectos clínicos e conduta. Arquivos Brasileiros de Endocrinologia \& Metabologia, v. 42, n. 4, p. 277-282, 1998.

MAIA, Ana Luiza Silva et al. Consenso brasileiro para o diagnóstico e tratamento do hipertireoidismo: recomendações do Departamento de Tireoide da Sociedade Brasileira de Endocrinologia e Metabologia. Arquivos brasileiros de endocrinologia \& metabologia. São Paulo. Vol. 57, n. 3 (abr. 2013), p. 205-232, 2013.

MENDONÇA, Keyla Mary Cavalheiro. Avaliação do Protocolo Com Atividade Fixa Em Portadores da Doença de Plummer Pós Radioiodoterapia (RIT). 2011. Dissertação de Mestrado. Universidade Federal de Pernambuco. VILAR, Lucio. Endocrinologia clínica. Rio de Janeiro: Guanabara Koogan, 2016. 6 ed. 